\title{
Localization of glucose-6-phosphatase activity and carbohydrates in boar caput epididymal principal cells
}

\author{
D. M. Geissbühler, A. E. Friess and M. H. Stoffel* \\ Department of Veterinary Anatomy, University of Bern Veterinary School, CH-3001 Bern, Switzerland
}

\begin{abstract}
Unidentified tubulovesicular profiles have been reported in the apical cytoplasm of boar caput epididymal principal cells in addition to vesicles considered to be involved in endocytosis and secretion. The main aim of the present study was to clarify the character of these organelles and to differentiate them from the endocytic apparatus. Glucose-6-phosphatase (G6Pase) activity was determined as the reporter enzyme of the endoplasmic reticulum (ER) and phosphotungstic acid was used to visualize carbohydrate moieties in both the proximal and distal caput. Phosphotungstic acid revealed the glycocalyx of the endocytic apparatus, which was similar in both regions studied, and also stained specific granules of the proximal caput. Glucose-6phosphatase showed the tubulovesicular profiles to be sparsely granulated ER that was poorly developed in the proximal caput and very abundant in the apical cytoplasm of the distal caput principal cells. The function of such large amounts of sparsely granulated ER with corresponding G6Pase activity in caput epididymal principal cells is unknown.
\end{abstract}

\section{Introduction}

The crucial role played by the epididymis in promoting the fertilizing ability of spermatozoa is now generally recognized (Cooper, 1986). The complexity of the subtle process of sperm maturation is reflected by regional differences in boar epididymal duct epithelial ultrastructure (Stoffel and Friess, 1994). The presence of abundant vesicles in the apical cytoplasm of caput epididymal principal cells is thought to reflect endocytic and secretory processes. However, small tubulovesicular profiles that are particularly abundant in the distal caput do not seem to fit either of these two categories and are thought to constitute oligogranular ER. Therefore, the present study was undertaken to determine the nature of these particular organelles and to differentiate them from the endocytic apparatus.

Glucose-6-phosphatase is the reporter enzyme for the ER (Nichols et al., 1984; Thorne-Tjomsland et al., 1991). Although this enzyme has recently been purified to enable production of monospecific antibodies (Hume et al., 1994), cytochemical demonstration of its hydrolytic activity (Robinson and Karnovsky, 1983; Van Norden and Frederiks, 1993) is currently the most widely used method for its detection. This technique has been used extensively to demonstrate G6Pase activity in liver, blood cells, testes and pancreatic islets (Leskes et al., 1971; Colilla et al., 1975; Nichols et al., 1984; Waddell and Burchell, 1988; Thorne-Tjomsland et al., 1991) and in epithelia lining the proximal convoluted tubules of

*Correspondence.

Received 26 November 1997. the kidney, ciliary body, small intestine, gall bladder, oviduct and epididymis (Hugon et al., 1971; Kanai et al., 1981, 1983; Thiéry et al., 1983; Asaka et al., 1991, 1993). In the present study, G6Pase cytochemistry was used to identify the ER. In addition, carbohydrates were stained with phosphotungstic acid to allow differentiation between elements of the endocytic apparatus and other organelles. This permitted ultrastructurally similar profiles to be distinguished.

\section{Materials and Methods}

\section{Sampling sites}

The caput epididymidis comprises the efferent ductules, an initial segment and the two segments called the proximal and distal caput. Tissue designated as proximal caput was collected from the bend of the caput epididymidis while samples originating from the lateral limb of the caput epididymidis are referred to as distal caput (Stoffel and Friess, 1994).

\section{Tissue fixation}

Epididymides from mature large white boars, Sus scrofa $\mathrm{f}$. dom. (approximately $110 \mathrm{~kg}$ body weight), were obtained at castration. The spermatic cord was cut as proximally as possible to preserve all the connections between the testicular and epididymal blood vessels. A bulb-headed cannula was directly inserted into the Ramus epididymalis 
proximalis within $5 \mathrm{~min}$ of removing the testes (Stoffel $e t$ al., 1990). The epididymides were perfused with $50 \mathrm{ml}$ lukewarm Hank's balanced salt solution (Gibco BRL, Paisley) until they were cleared of blood. Perfusion with $50-100 \mathrm{ml}$ of fixative $(2.5 \%$ glutaraldehyde in $43 \mathrm{mmol}$ $\mathrm{Na}_{2} \mathrm{SO}_{4} \mathrm{l}^{-1}, 16 \mathrm{mmol} \mathrm{NaHCO}_{3} \mathrm{l}^{-1}, 10 \mathrm{mmol}$ sodium acetate $\mathrm{l}^{-1}$,

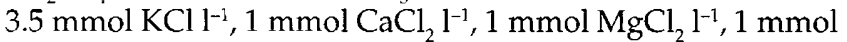
$\mathrm{D}(+)$-glucose $\mathrm{l}^{-1}, 1.6 \mathrm{mmol} \mathrm{Na}_{2} \mathrm{HPO}_{4} \mathrm{l}^{-1}, 0.4 \mathrm{mmol} \mathrm{NaH} \mathrm{PO}_{4} \mathrm{l}^{-1}$ and $33 \mathrm{mmol} \mathrm{D}(+)$-sucrose $\mathrm{l}^{-1}, \mathrm{pH} 7.4$; modified after $\mathrm{Xu}$ and Ling, 1994) followed immediately and was maintained for 10 min. For G6Pase cytochemistry, small blocks of tissue were excised, immersed in fixative at $4^{\circ} \mathrm{C}$ for $20 \mathrm{~min}$ and then washed at $4^{\circ} \mathrm{C}$ in $0.1 \mathrm{~mol}$ cacodylate $1^{-1}$ buffer containing $6.8 \%(\mathrm{w} / \mathrm{v})$ sucrose and $0.2 \mathrm{~mol}$ glycine $\mathrm{l}^{-1}, \mathrm{pH} 7.4$. Tissue blocks used for staining with phosphotungstic acid were transferred to fixative for a further $2 \mathrm{~h}$. Diluted Karnovsky's fixative $(1 \%(\mathrm{w} / \mathrm{v})$ paraformaldehyde, $1.25 \%$ glutaraldehyde in $0.1 \mathrm{~mol}$ cacodylate $\mathrm{l}^{-1}$ buffer with $2 \mathrm{mmol} \mathrm{CaCl}_{2} \mathrm{l}^{-1}, \mathrm{pH} 7.4$ ) was used for tissue stained with phosphotungstic acid.

\section{Glucose-6-phosphatase}

Cryostat sections of about 8-9 $\mu \mathrm{m}$ were transferred to poly-L-lysine-coated slides and incubated for $1 \mathrm{~h}$ at room temperature in the following reaction medium (modified after Kanai et al., 1983): $3.7 \mathrm{mmol}$ glucose-6-phosphate $1^{-1}$

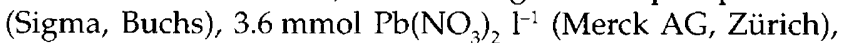

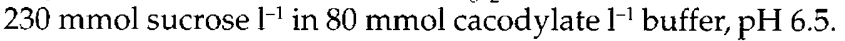
Substrate was omitted from control reactions. After thorough washing in distilled water, staining was enhanced by incubating the sections in $1 \%(\mathrm{v} / \mathrm{v})$ ammonium sulphide for $2 \mathrm{~min}$.

For electron microscopy, thin slices of about $150-200 \mu \mathrm{m}$ were produced under a dissecting microscope with razor blades. The cytochemical reaction was obtained by preincubating for $1 \mathrm{~h}$ at room temperature and subsequently for $1 \mathrm{~h}$ at $37^{\circ} \mathrm{C}$ in the following medium (modified after Kalicharan et al., 1985): $4 \mathrm{mmol}$ glucose-6-phosphate $\mathrm{l}^{-1}$ and $2 \mathrm{mmol}$ cerium chloride $\mathrm{l}^{-1}$ (Fluka Chemie AG, Buchs) in $50 \mathrm{mmol}$ Tris-maleate $\mathrm{l}^{-1}$ buffer, $\mathrm{pH}$ 6.5. Substrate was omitted from control incubations. Tissue was then postfixed with $1 \%(\mathrm{w} / \mathrm{v}) \mathrm{OsO}_{4}$ in $0.1 \mathrm{~mol}$ cacodylate $\mathrm{l}^{-1}$ buffer, dehydrated in an ascending ethanol series and embedded in an epon-araldite mixture. Ultrathin sections were examined in a Zeiss 109 electron microscope.

\section{Phosphotungstic acid}

After aldehyde fixation, tissue blocks were embedded in $\mathrm{K} 4 \mathrm{M}$ (Fluka Chemie $\mathrm{AG}$, Buchs) at $0^{\circ} \mathrm{C}$. Incubations with phosphotungstic acid were carried out according to Rambourg (1967). Ultrathin sections of about $90 \mathrm{~nm}$ were floated for $2 \mathrm{~min}$ on a solution of $1 \%(\mathrm{w} / \mathrm{v})$ phosphotungstic acid in $10 \%(\mathrm{w} / \mathrm{v})$ chromic acid (E. Merck AG, Zürich) at pH0.3 using self-made polyethylene rings for transfer (Farragiana and Marinozzi, 1979). After several washes in distilled water, sections were picked up on copper grids and examined in a Zeiss 109 electron microscope.

\section{Results}

\section{Glucose-6-phosphatase}

Reaction product on paraffin wax sections was localized in the upper half of the epithelium except for a faint staining along the basement membrane (Figs 1a and 2a). Lead precipitate was particularly abundant along the apical plasmalemma. This strongly positive apical band was more prominent in the distal caput than in the proximal caput. In both regions the band was separated from a positive supranuclear zone by a narrow non-reactive belt. Incubation without substrate resulted in a low background staining along the basement membrane and occasionally along the luminal cell border (Figs $1 \mathrm{~b}$ and $2 \mathrm{~b}$ ).

In the electron microscope, cerium phosphate was identified as a coarse extracellular deposit along the stereocilia in the proximal caput only and intracellularly as a finely granular reaction product in both epididymal regions studied. Precipitate was observed along the nuclear membrane, in Golgi stacks, and in the trans-Golgi network (Figs 1c,d and 2c). Long parallel strands in the infra-, periand supranuclear cytoplasm were also observed (Figs 1d and 2c). Small tubulovesicular profiles filled with precipitate were detected in the apical cytoplasm. These were scarce in the proximal caput (Fig. 1c) and abundant in distal caput principal cells, where they occupied the apical protrusions up to the plasma membrane (Fig. 2d,e). However, no communication was observed between vesicular membranes and plasmalemma. Control reactions were negative (Fig. 3).

\section{Phosphotungstic acid}

Phosphotungstic acid stained the apical plasmalemma including spherical and tubular pits in both the proximal and distal caput (Fig. 4a,c), and gave a faint reaction on the lateral cell membranes (Fig. 4 b) and the basement membrane. In addition, the membranes of numerous electron-lucent tubules and vesicles in the apical cytoplasm were positive (Fig. 4a,c). Continuity between the membrane of the tubulovesicular profiles and the apical plasmalemma was frequently observed (Fig. 4a). However, phosphotungstic acid staining became fainter with increasing distance from the apical cell border. The granules characteristic of the proximal caput were positive (Fig. 4b). Golgi stacks were also positive; nuclei, mitochondria and ER were completely negative.

\section{Discussion}

The main purpose of the present study was to identify ultrastructurally similar vesicular profiles in the apical cytoplasm of caput epididymal principal cells. Glucose-6phosphatase activity was used as a marker for the ER and phosphotungstic acid identified the endocytic apparatus. Vesicular profiles negative for both reactions were considered to be part of the secretory pathway.

Phosphotungstic acid revealed the glycocalyx of the apical 

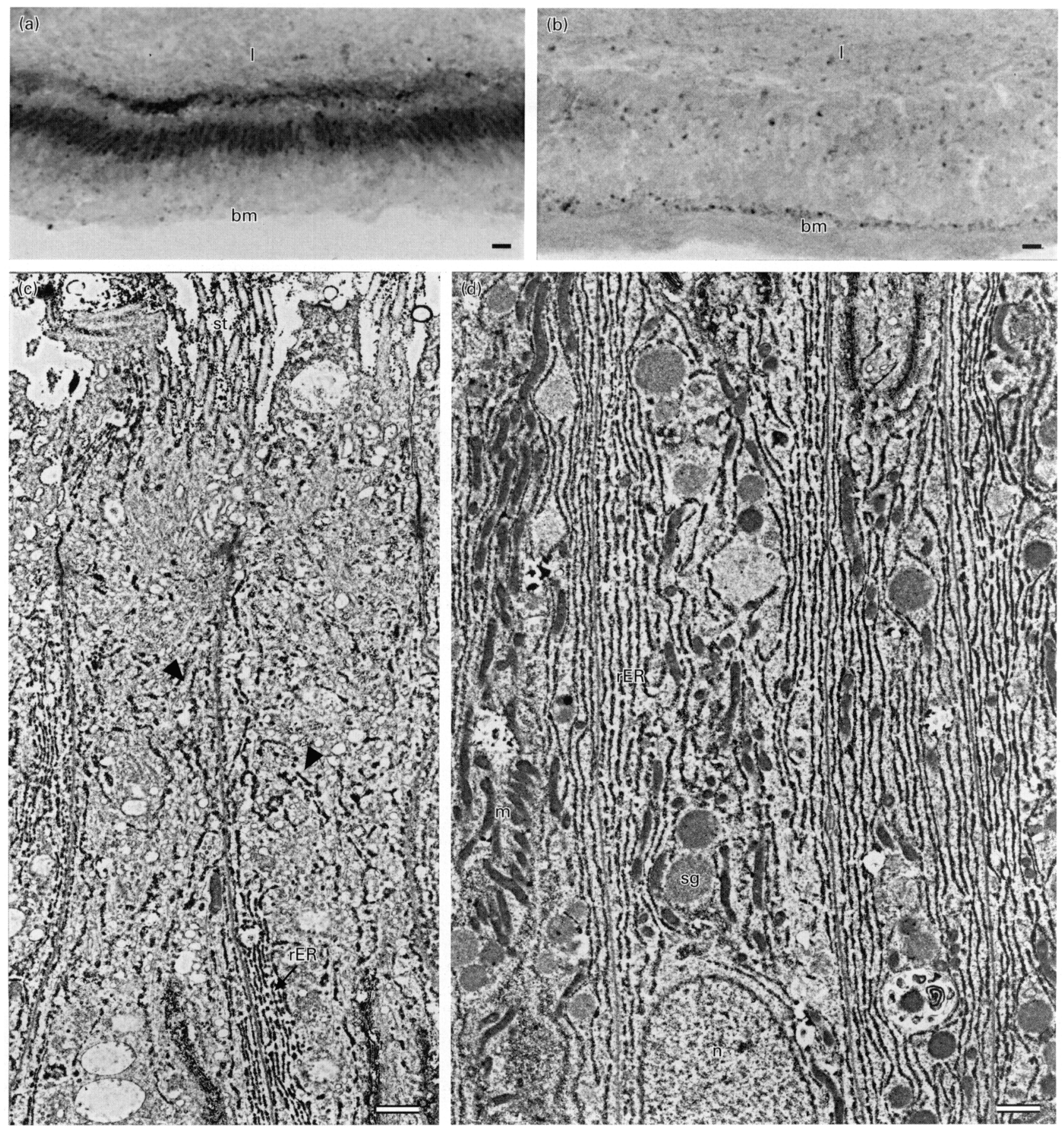

Fig. 1. Glucose-6-phosphatase reaction in boar proximal caput epididymal epithelium. (a) Light microscopy reveals a moderately positive apical band separated from the supranuclear reactive zone by a narrow unstained strip. (b) Control reaction without substrate showing very faint background staining along the basement membrane. (c) In the apical zone, a coarse reaction product is observed on the stereocilia, while precipitate in the rough endoplasmic reticulum is finely granular. A similar deposit is present in a loosely arranged network of tubulovesicular profiles (arrowheads). (d) Prominent staining of parallel strands of rough endoplasmic reticulum, Golgi apparatus and nuclear membrane. bm, basement membrane; l, lumen; $m$, mitochondria; $n$, nucleus; rER, rough endoplasmic reticulum; $\mathrm{sg}$, specific granules; st, stereocilia. Scale bars represent $10 \mu \mathrm{m}$ in (a) and (b) and $1 \mu \mathrm{m}$ in (c) and (d).

plasmalemma and also labelled the membranes of the tubulovesicular profiles involved in absorption. This allowed the organelles belonging to the endocytic apparatus and sparsely granulated ER to be distinguished on the basis of their shape and distribution pattern. On the basis of the number of vesicles present, proximal and distal caput appear to be equally involved in absorption. Phosphotungstic acid also stained the granules that are characteristic of the 

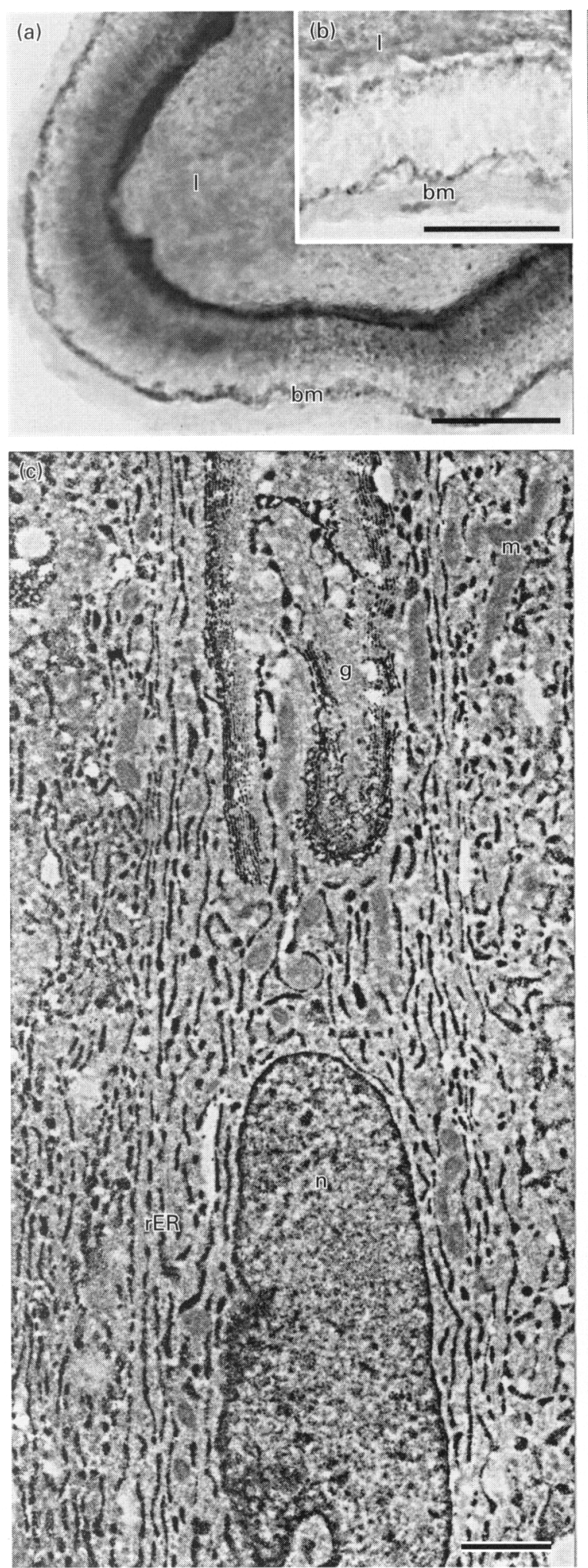
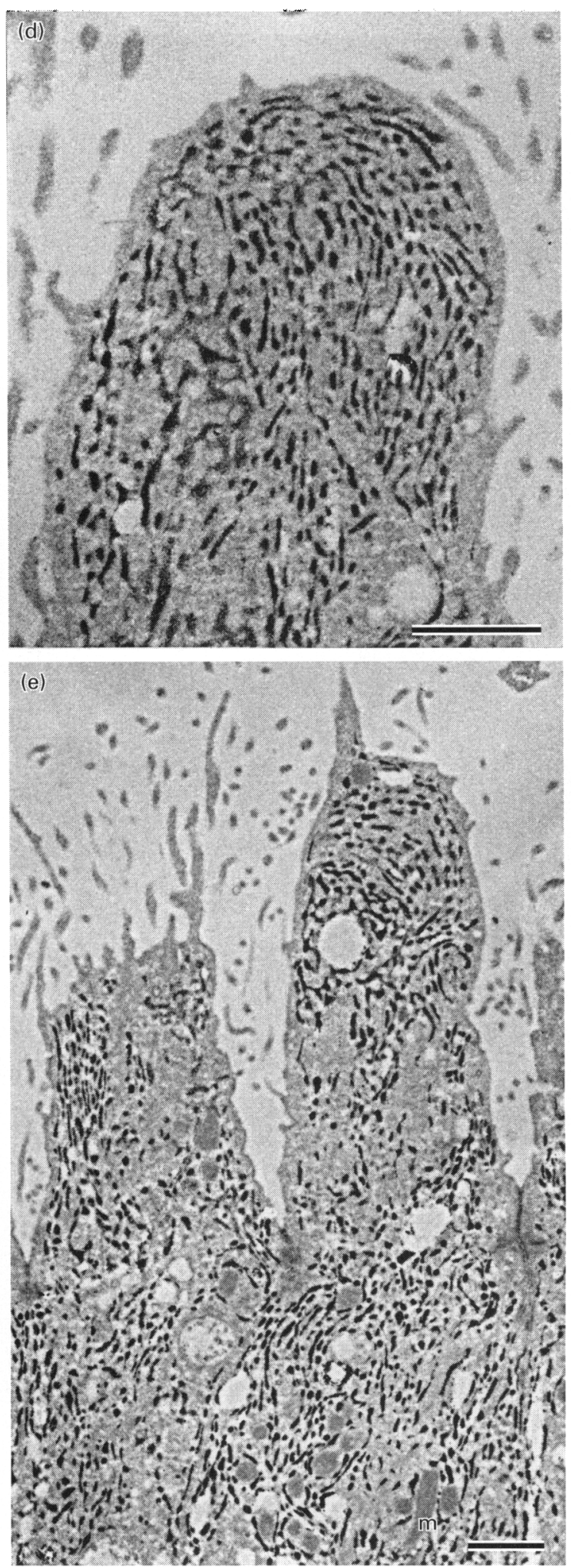

Fig. 2. Glucose-6-phosphatase reaction in boar distal caput epididymal epithelium. (a) A strongly positive apical zone is narrowly separated from moderately stained supranuclear cytoplasm. (b) Control reaction without substrate showing very faint background staining along the basement membrane and luminal border. (c) Dark staining of nuclear membrane, rough endoplasmic reticulum and Golgi apparatus. (d,e) Extensive tubulovesicular profiles in the apical cytoplasm in close proximity to, but lacking continuity with, the plasmalemma. bm, basement membrane; g, Golgi apparatus; 1 lumen; $\mathrm{m}$, mitochondria; $\mathrm{n}$, nucleus; $r E R$, rough endoplasmic reticulum. Scale bars represent $100 \mu \mathrm{m}$ in (a) and (b) and $1 \mu \mathrm{m}$ in (c)-(e). 


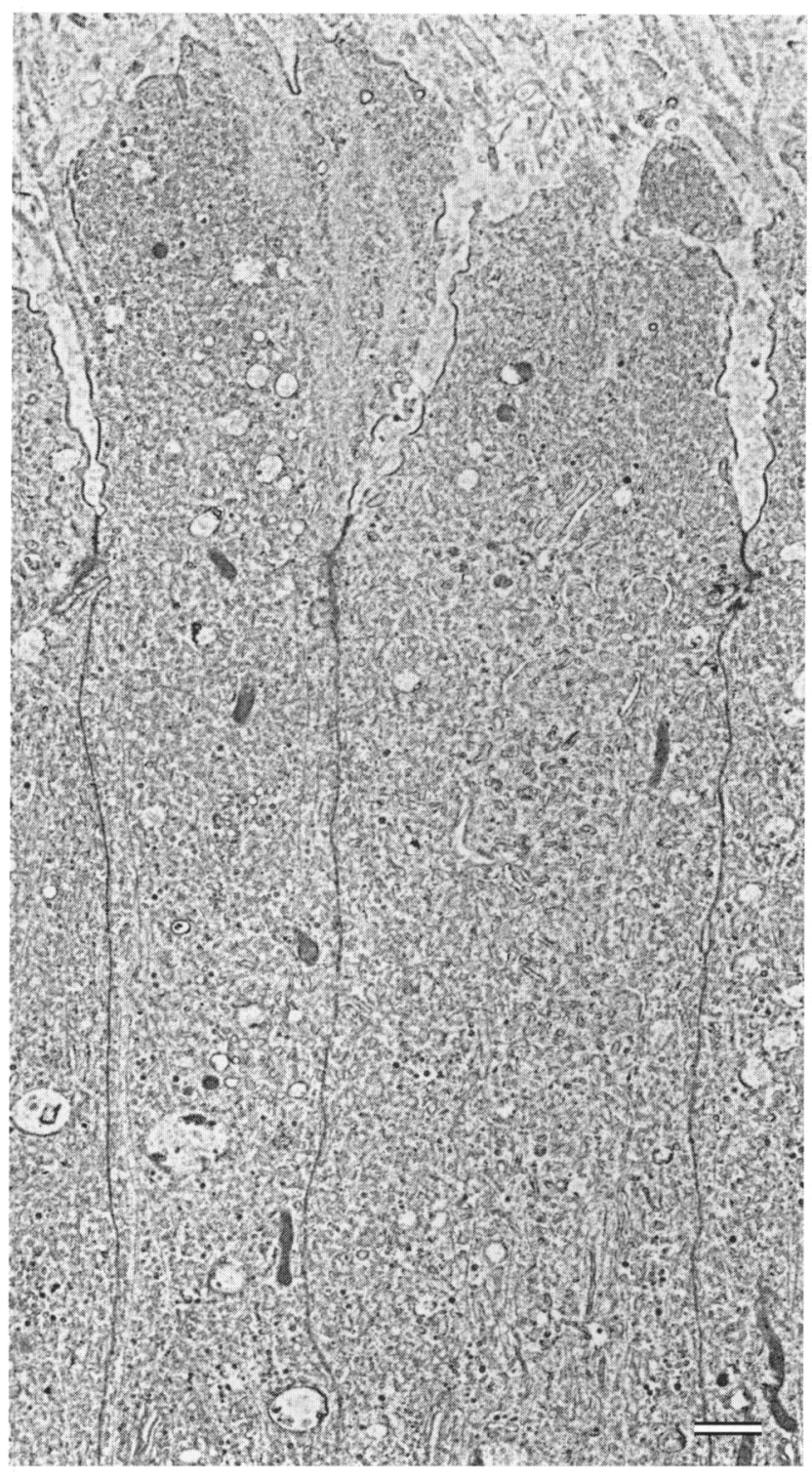

Fig. 3. Control incubation of boar proximal caput epididymal principal cells for glucose-6-phosphatase activity in the absence of substrate. No reaction product is observed. Scale bar represents $1 \mu \mathrm{m}$.

proximal caput, which have been shown to contain antagglutinin (Dacheux and Dacheux, 1987). Antagglutinin is a secretory product of the caput epididymidis in boars. Immunocytochemical detection of antagglutinin in rough ER, Golgi apparatus, vesicles and epididymal lumen suggests it is a glycoprotein, which explains staining of the granules with phosphotungstic acid. However, the granules are thought to be sites of degradation rather than being part of the secretory pathway (Dacheux and Dacheux, 1987).

Glucose-6-phosphatase is a reporter enzyme for the ER (Allen, 1961; Nichols et al., 1984; Thorne-Tjomsland et al., 1991; Burchell et al., 1994) and is a useful tool for determination of complex membrane systems (Leskes et al., 1971; Robinson and Karnovsky, 1983). However, glucose-6phosphate is not only hydrolysed by the specific enzyme
G6Pase but also by other phosphatases (Allen, 1961; Nordlie, 1979; Nichols et al., 1984). In addition to different pH optima, these enzymes differ substantially in lability. While G6Pase is susceptible to inactivation by fixation, both acid and alkaline phosphatases remain cytochemically active even after prolonged exposure to aldehyde fixatives (Sabatini et al., 1963). The presence of a coarse precipitate along the apical plasmalemma in proximal caput principal cells and along the cell membranes of basal cells in both epididymal regions studied (not shown) was independent of any fixation parameter. Inayama et al. (1995) showed alkaline phosphatase to be a marker for basal cells in rabbit airways. In addition, the presence of this enzyme has been reported in the epididymides of bulls (Sinowatz, 1981) and boars (Wrobel and Fallenbacher, 1974). In both species, basal cells throughout the epididymal duct are positive for alkaline phosphatase, whereas stereocilia in the distal caput display little or no enzymic activity. This finding is in agreement with the present findings and thus the staining in these areas is considered to be due to non-specific hydrolysis by alkaline phosphatase.

The finely granular reaction product within principal cells was only observed after minimal fixation. Indeed, adequate preservation of ultrastructure without substantial loss of intracellular enzymic activity was a problem. The precipitate observed in rough ER and nuclear envelope was taken as a reference for the specific cytochemical reaction. Therefore, the presence of an identical reaction product in the Golgi apparatus and in numerous irregular tubulovesicular profiles was considered to reflect G6Pase activity. Although Golgi elements are considered to be G6Pase-negative, there is increasing evidence that this enzyme is a constituent of this organelle in some cells. Glucose-6-phosphatase activity has been demonstrated in Golgi stacks and in the trans-Golgi network of principal cells in the initial segment of the rat epididymal duct (Hermo et al., 1991) and in spermatocytes, spermatids and Leydig cells but not Sertoli cells of rat testis (Thorne-Tjomsland et al., 1991).

Glucose-6-phosphatase-positive tubulovesicular profiles of sparsely granulated ER were detected close to the Golgi apparatus and also intermingled with other vesicular structures at the very apex of the cells. Close apposition of oligogranular ER with both cis- and trans-Golgi elements has been described in detail in the rat epididymis (Hermo et al., 1991). Whereas close proximity of sparsely granulated ER to cis-Golgi elements is explained by intracellular traffic, the functional basis for the proximity of sparsely granulated ER to the trans-Golgi is unknown. However, the most interesting observation of this study was the large amount of G6Pase-positive sparsely granulated ER in the apical cytoplasm of distal principal cells. This is particularly interesting because the intracellular distribution of smooth and oligogranular ER appears to be very specific. In ruminant Sertoli cells, for example, the smooth ER is localized basally and in close association with spermatids (Wrobel et al., 1995). A secretory mechanism that bypasses the Golgi apparatus has been suggested on the basis of the intimate topographical relationship between sparsely granulated ER and apical plasmalemma in the initial segment of the rat epididymis (Hoffer et al., 1973). Although 

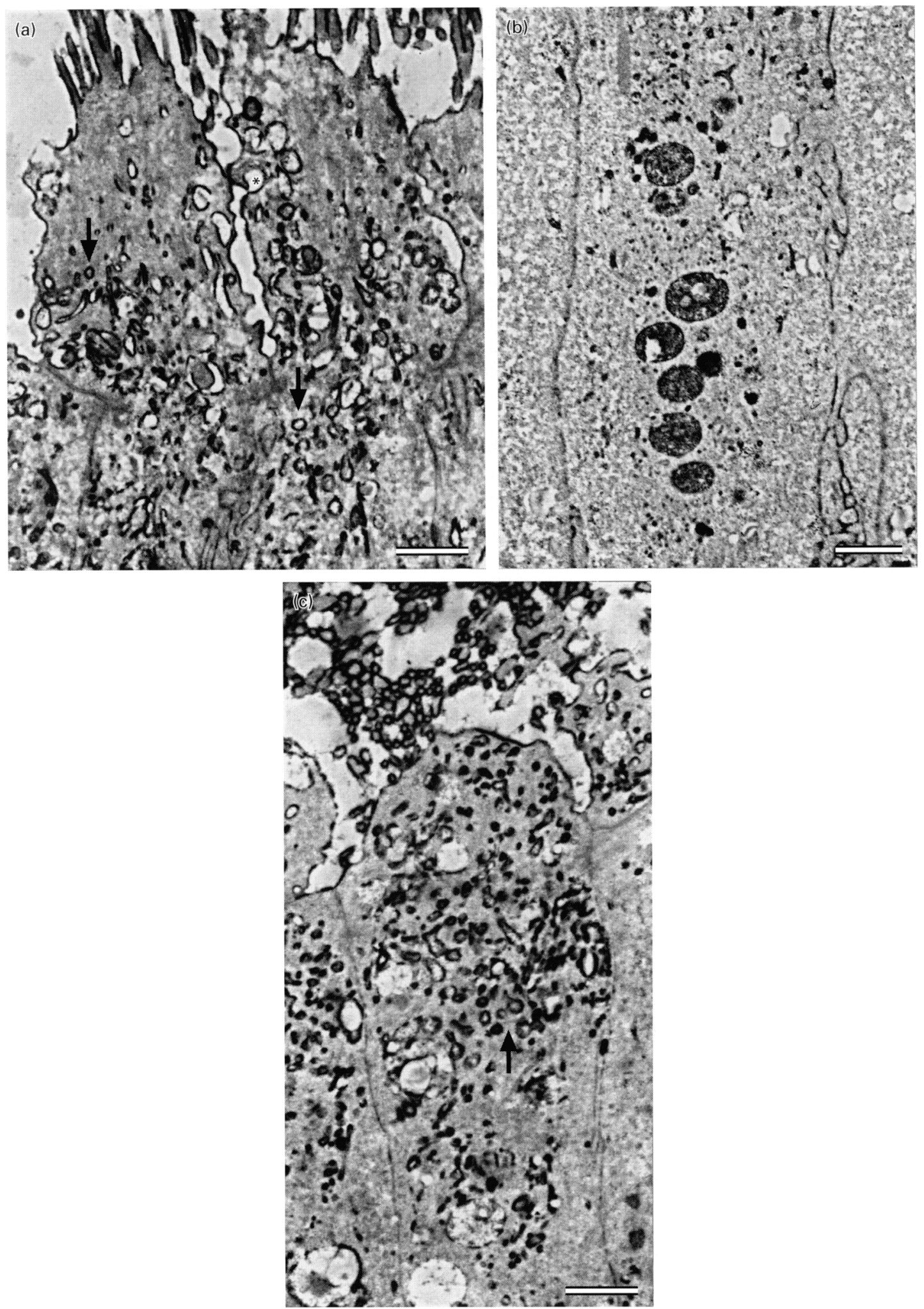

Fig. 4. Staining of boar $(\mathrm{a}, \mathrm{b})$ proximal and (c) distal caput epididymal principal cells with phosphotungstic acid. (a) Stereocilia, vesicular and tubular pits $\left(^{*}\right.$ ) as well as the endocytic apparatus (arrows) are clearly outlined. (b) Granules that are characteristic of proximal caput principal cells are reactive. (c) The apical plasmalemma and numerous endocytic apparatus profiles (arrow) are stained. Scale bars represent $1 \mu \mathrm{m}$. 
the transport carrier from the Golgi apparatus to the lumen has been tentatively identified (Hermo et al., 1994), autoradiographic and immunocytochemical studies have shown that synthesis and secretion of epididymal proteins involves the ER and the Golgi apparatus (Flickinger, 1985; Dacheux and Dacheux, 1987).

In the liver, G6Pase catalyses the last step of both glycogenolysis and gluconeogenesis and thus plays a key role in blood glucose homeostasis (Nordlie, 1985). The presence of G6Pase activity in other organs is usually considered to be a mechanism by which glucose is released into a luminal environment, for example, the aqueous humour (Asaka et al., 1991), oviductal fluid (Asaka et al., 1993) and epididymal fluid (Kanai et al., 1983). In fact, glucose has been shown to occur in the luminal environment after its normal contents are removed (Cooper and Waites, 1979) and it has been suggested that sperm cells prevent accumulation of reducing sugars in epididymal duct fluid by using glucose as a substrate (Brooks, 1979a). Therefore, such a function would be compatible with the apical localization of G6Pase in caput epididymal principal cells. However, rapid transport of glucose from the bloodstream across the epididymal epithelium via a facilitated diffusion mechanism is an alternate route by which glucose can be supplied to luminal fluid (Brooks, 1979b; Hinton and Howards, 1982).

Glucose-6-phosphatase may be involved in generating NADPH via the hexose-monophosphate shunt (Colilla et al., 1975). NADPH, in turn, is needed to reduce testosterone to dihydrotestosterone. Dihydrotestosterone is about twice as potent as the substrate and is crucial in maintaining high levels of androgen activity within tissues (Luke and Coffey, 1994). In boars, luminal concentrations of dihydrotestosterone exceed those of testosterone and the proximal epididymis contains more androgens than the distal region (Aafjes and Vreeburg, 1972). In addition, the activity of epididymal G6Pase has been shown to be controlled by circulating testosterone in mice (Kanai et al., 1983). The irreversible interconversion of testosterone to dihydrotestosterone is catalysed by $5 \alpha$-reductase. However, $5 \alpha$-reductase activity is known to be highest in the central caput of the bovine epididymis (Hammerstedt and Amann, 1976), a region equivalent to the segment referred to as the proximal caput in the present paper. In rats, immunocytochemical labelling of $5 \alpha$-reductase was most intense in discrete lobules of the initial segment, in which it was restricted to the infranuclear zone of principal epididymal cells. Intense supranuclear staining for the enzyme was typical for the proximal caput, whereas weak staining was observed throughout the cytoplasm in distal regions (Viger and Robaire, 1994; Robaire and Viger, 1995). Therefore, the distribution pattern of $5 \alpha$-reductase in rats is not the same as the localization of G6Pase activity in the corresponding segments of the boar epididymis.

Further investigations are required to determine the functional implications of abundant profiles of sparsely granulated ER with corresponding G6Pase activity in boar caput epididymal principal cells.

The outstanding technical assistance of C. Furer and of C. Hug and the excellent photographic work of S. König are gratefully acknowledged.

\section{References}

Aafjes JH and Vreeburg JT (1972) Distribution of $5 \alpha$-dihydrotestosterone in the epididymis of bull and boar, and its concentration in rat epididymis after ligation of efferent testicular ducts, castration and unilateral gonadectomy Journal of Endocrinology 53 85-93

Allen JM (1961) The histochemistry of glucose-6-phosphatase in the epididymis of the mouse Journal of Histochemistry and Cytochemistry 9 681-689

Asaka Y, Watanabe J, Kanai K and Kanamura S (1991) High glucose-6phosphatase activity in non-pigmented epithelial cells of rabbit ciliary body Journal of Histochemistry and Cytochemistry 39 1113-1120

Asaka Y, Watanabe J, Amatsu T and Kanamura S (1993) Significance of high glucose-6-phosphatase activity in rat oviduct epithelium Journal of Histochemistry and Cytochemistry 41 1841-1848

Brooks DE (1979a) Biochemical environment of sperm maturation. In The Spermatozoon pp 23-34 Eds DW Fawcett and JM Bedford. Urban \& Schwarzenberg, Baltimore

Brooks DE (1979b) Carbohydrate metabolism in the rat epididymis: evidence that glucose is taken up by tissue slices and isolated cells by a process of facilitated transport Biology of Reproduction 21 19-26

Burchell A, Allan BB and Hume R (1994) Glucose-6-phosphatase proteins of the endoplasmic reticulum Molecular Membrane Biology 11 217-227

Colilla W, Jorgenson RA and Nordlie RC (1975) Mammalian carbamyl phosphate: glucose phosphotransferase and glucose-6-phosphate phosphohydrolase: extended tissue distribution Biochimica et Biophysica Acta 377 116-125

Cooper TG (1986) The Epididymis, Sperm Maturation and Fertilization SpringerVerlag, Berlin

Cooper TG and Waites GMH (1979) Investigation by luminal perfusion of the transfer of compounds into the epididymis of the anaesthetized rat journal of Reproduction and Fertility 56 159-164

Dacheux F and Dacheux J-L (1987) The intracellular pathway of antagglutinin secretion in the boar caput epididymidis as revealed by immunogold labelling Cell and Tissue Research 249 89-99

Farragiana T and Marinozzi V (1979) Phosphotungstic acid staining of polysaccharide-containing structures on epoxy embedded tissues Journal of Submicroscoscopic Cytology $11263-265$

Flickinger CJ (1985) Radioautographic analysis of the secretory pathway for glycoproteins in principal cells of the mouse epididymis exposed to [ $\left.{ }^{3} \mathrm{H}\right]$ fucose Biology of Reproduction 32 377-389

Hammerstedt RH and Amann RP (1976) Interconversions of steroids by intact bovine sperm and epididymal tissue Biology of Reproduction 15 686-694

Hermo L, Green H and Clermont Y (1991) Golgi apparatus of epithelial principal cells of the epididymal initial segment of the rat: structure, relationship with endoplasmic reticulum, and role in the formation of secretory vesicles Anatomical Record 229 159-176

Hermo L, Oko R and Morales CR (1994) Secretion and endocytosis in the male reproductive tract: a role in sperm maturation International Review of Cytology 154 105-189

Hinton BT and Howards SS (1982) The rat testis and epididymis can transport ${ }^{3} \mathrm{H}-3-\mathrm{O}$-methyl-D-glucose, ${ }^{3} \mathrm{H}$-inositol, and ${ }^{3} \mathrm{H}$ - $\alpha$-aminoisobutyric acid across its epithelia in vivo. Biology of Reproduction 27 1181-1189

Hoffer AP, Hamilton DW and Fawcett DW (1973) The ultrastructure of the principal cells and intraepithelial leucocytes in the initial segment of the rat epididymis Anatonical Record 175 169-202

Hugon JS, Maestraci D and Ménard D (1971) Glucose-6-phosphatase activity in the intestinal epithelium of the mouse Journal of Histochemistry and Cytochemistry $19515-525$

Hume R, Bell JE, Hallas A and Burchell A (1994) Immunohistochemical localization of glucose-6-phosphatase in developing human kidney Histochemistry 101 413-417

Inayama Y, Tomiyama I, Kitamura H, Nakatani Y, Ito T, Nozawa A, Usuda Y and Kanisawa M (1995) Alkaline phosphatase reactivity in rabbit airway epithelium: a potentially useful marker for airway basal cells Histochemistry and Cell Biology 104 191-198

Kalicharan D, Hulstaert CE and Hardonk MJ (1985) Prevention of penetration hindrance in cerium-based glucose-6-phosphatase cytochemistry by freezing tissue in melting nitrogen Histochemistry 82 287-292

Kanai K, Asada-Kubota $\mathbf{M}$ and Kanamura S (1981) Ultrastructural localization of glucose 6-phosphatase activity in the cells of epididymis of the mouse Experientia 37 509-511

Kanai K, Kanamura S, Watanabe J, Asada-Kubota $M$ and Yoshikawa $M$ (1983) Effect of castration and testosterone replacement on high glucose 6- 
phosphatase activity in principal cells of the mouse epididymis Anatomical Record 207 289-295

Leskes A, Siekevitz P and Palade GE (1971) Differentiation of endoplasmic reticulum in hepatocytes. I. Glucose-6-phosphatase distribution in situ. Journal of Cell Biology 49 264-287

Luke MC and Coffey DS (1994) The male sex accessory tissues: structure, androgen action and physiology. In The Physiology of Reproduction pp 1435-1487 Eds E Knobil, J Neill, L Ewing, G Greenwald, C Markert and D Pfaff. Raven Press Ltd, New York

Nichols BA, Setzer PY and Bainton DF (1984) Glucose-6-phosphatase as a cytochemical marker of endoplasmic reticulum in human leukocytes and platelets Journal of Histochemistry and Cytochemistry 32 165-171

Nordlie RC (1979) Multifunctional glucose-6-phosphatase: cellular biology Life Sciences 24 2397-2404

Nordlie RC (1985) Fine tuning of blood glucose concentrations Trends in Biochenical Science $1070-78$

Rambourg A (1967) Détection des glycoprotéines en microscopie électronique: coloration de la surface cellulaire et de l'appareil de Golgi par un mélange acide chromique-phosphotungstique Comptes Rendus de l'Académie des Sciences (Paris) 265 1426-1433

Robaire B and Viger RS (1995) Regulation of epididymal epithelial cell functions Biology of Reproduction 52 226-236

Robinson JM and Karnovsky MJ (1983) Ultrastructural localization of several phosphatases with cerium Journal of Histochemistry and Cytochemistry 31 1197-1208

Sabatini DD, Bensch K and Barnett RJ (1963) Cytochemistry and electron microscopy. The preservation of cellular ultrastructure and enzymatic activity by aldehyde fixation Journal of Cell Biology 17 19-58

Sinowatz F (1981) Ultrastrukturelle und histochemische untersuchungen am ductus epididymidis des rindes Fortschritte der Veterinärmedizin 32 1-99
Stoffel MH and Friess AE (1994) Morphological characteristics of boar efferent ductules and epididymal duct Microscopy Research and Technique 29 411-431

Stoffel M, Friess AE and Kohler T (1990) Die vaskularisation des ebernebenhodens unter besonderer berücksichtigung der perfusionsfixation Schweizer Archiv für Tierheilkunde 132 571-579

Thiéry G, Gaffiero $\mathbf{P}$ and Bergeron $\mathbf{M}$ (1983) Three-dimensional characteristics of the endoplasmic reticulum in the columnar cells of the rat small intestine: an electron microscopy study in thick sections Americant Journal of Anatomy 167 479-493

Thorne-Tjomsland G, Clermont Y and Tang X (1991) Glucose-6-phosphatase activity of endoplasmic reticulum and Golgi apparatus in spermatocytes and spermatids of the rat: an electron microscopic cytochemical study Biology of the Cell 71 33-41

Van Norden CJF and Frederiks WM (1993) Cerium methods for light and electron microscopical histochemistry Journal of Microscopy 171 3-16

Viger RS and Robaire B (1994) Immunocytochemical localization of 4-ene steroid $5 \alpha$-reductase type 1 along the rat epididymis during postnatal development Endocrinology 134 2298-2306

Waddell ID and Burchell A (1988) The microsomal glucose-6-phosphatase enzyme of pancreatic islets Biochemical Journal 255 471-476

Wrobel KH and Fallenbacher E (1974) Histologische und histochemische untersuchungen am nebenhodenepithel erwachsener eber Zuchthygiene 9 $20-31$

Wrobel KH, Reichold J and Schimmel M (1995) Quantitative morphology of the ovine seminiferous epithelium Annals of Anatomy 177 19-32

$\mathrm{Xu}$ J and Ling E-A (1994) Studies of the ultrastructure and permeability of the blood-brain barrier in the developing corpus callosum in postnatal rat brain using electron dense tracers Journal of Anatomy 184 227-237 